\title{
Extraction, purification, methylation and GC-MS analysis of short-chain carboxylic acids for metabolic flux analysis
}

Nathan D. Tivendale ${ }^{\mathrm{a} *}$, Erin M. Jewett, Adrian D. Hegeman ${ }^{\mathrm{a}, \mathrm{b}}$, Jerry D. Cohen ${ }^{\mathrm{a}}$

${ }^{a}$ Department of Horticultural Science and Microbial and Plant Genomics Institute

${ }^{\mathrm{b}}$ Department of Plant Biology

University of Minnesota, St. Paul, MN, 55108 USA

*Corresponding author. ntivenda@umn.edu, Ph: 612-625-7575, fax: 612-624-4941, 305

Alderman Hall, 1970 Folwell Ave, St Paul, MN 55108

Subject category: Chromatographic techniques and Mass spectrometry. 


\section{Abstract}

Dynamic metabolic flux analysis requires efficient and effective methods for extraction, purification and analysis of a plethora of naturally-occurring compounds. One area of metabolism that would be highly informative to study using metabolic flux analysis is the tricarboxylic acid (TCA) cycle, which consists of short-chain carboxylic acids. Here, we describe a newly-developed method for extraction, purification, derivatization and analysis of short-chain carboxylic acids involved in the TCA cycle. The method consists of snap-freezing the plant material, followed by maceration and a $12-15 \mathrm{~h}$ extraction at $-80^{\circ} \mathrm{C}$. The extracts are then subject to reduction (to stabilize $\beta$-keto acids), purified by strong anion exchange solid phase extraction and methylated with methanolic $\mathrm{HCl}$. This method could also be readily adapted to quantify many other short-chain carboxylic acids.

\section{Keywords}

Gas chromatography-mass spectrometry, tricarboxylic acid cycle, methylation, carboxylic acid, polar metabolites, metabolic flux

\section{$1 \quad$ Introduction}

The tricarboxylic acid (TCA) cycle is central in carbon metabolism and energy generation in all aerobic organisms and consists of eight low-molecular-weight polar intermediates, including $\alpha$ ketoglutaric acid, citric acid, malic acid, succinic acid, fumaric acid and oxaloacetic acid [1]. Given the central role of the TCA cycle, measurement of the flux through this cycle under a variety of environmental conditions would provide important information regarding cellular 
metabolism. Many TCA flux modes have been proposed, [2] but most rely on computer simulations or in vitro reaction studies [e.g. 3], require large amounts of tissue (which is often impracticable), or require extensive sample processing prior to analysis [4]. Furthermore, many of the current derivatization strategies, which rely on trimetylsilylation, suffer from greatly reduced extractable isotopomer data because the mass spectrum (MS) is dominated by the trimethylsilyl (TMS) fragment [e.g. 5]. The method described herein overcomes each of these problems, thus allowing a more accurate estimate of metabolic flux through the TCA cycle. Dynamic metabolic flux analysis (MFA), a powerful technique for estimation of fluxes under non-steady state conditions, requires robust, efficient and sensitive methods for detecting and quantifying metabolites that are often found at low levels (see [6] and [7] for reviews of the process of metabolic flux analysis). To obtain the most accurate flux estimates, MFA requires measurement of two variables for each metabolite over a range of time-points to facilitate flux estimation: absolute metabolite abundance and isotopic label incorporation from labeling experiments. Low-molecular-weight polar compounds present a problem for commonly-used analytical MFA analysis procedures. The analytical methods of choice for MFA typically consist of gas chromatography or liquid chromatography (GC and LC, respectively) coupled with mass spectrometry (MS) or nuclear magnetic resonance (NMR) spectroscopy [6,8]. However, these analytical methods are difficult to apply to polar metabolites, which are not retained on reverse phase LC columns or volatile enough to produce sharp, well-resolved peaks on GC and often cannot be obtained in sufficient quantify for NMR. While it is possible to achieve retention of these compounds using hydrophilic interaction chromatography, retention times and fragmentation patterns are far less reproducible on LC-MS compared to GC-MS. A further 
advantage of GC-MS over LC-MS is that the number of fragment ions produced by electron impact is greater than the number produced by softer LC-MS ionization techniques (e.g. Electrospray Ionization and Atmospheric Pressure Chemical Ionization) and thus GC-MS offers more positional isotopomer information. Here, we report a new extraction, purification, derivatization and analysis method to allow estimation of TCA cycle flux using milligram quantities of tissue. In this study, we examine several methods for derivatizing short-chain carboxylic acids and determine the most efficient and appropriate method, using four representative acids from the TCA cycle, to enable analysis of these polar metabolites by GCMS. We also demonstrate how the best method can be applied to measure the levels of six TCA cycle intermediates in extracts from greater duckweed (Spirodela polyrhiza). While there was initially some interest in the chromatographic properties of methyl esters of short-chain carboxylic acids $[9,10]$, interest has declined significantly over the last half-century as researchers have favored the relatively easily-synthesized TMS derivatives. As such, there has yet to be developed a comprehensive procedure for isolation, purification, methylation and analysis of short-chain carboxylic acids from biological material. For metabolic flux analysis, the development of such a procedure would have significant advantages over trimethylsilylation, chief of which is simplification of the interpretation of isotopic label incorporation data from isotopic labeling experiments; each carbon introduced by the derivatization reagent brings with it a small portion of naturally-occurring labeled material. For TCA cycle intermediates, trimethylsilylation adds six or nine carbon atoms. Using methylation, we introduce only two or three carbons to the analytes, so we minimize the disturbance of the isotopic envelope, thus allowing more straightforward interpretation of labeling data from isotopic tracer experiments. 


\section{Materials and Methods}

\subsection{Chemicals}

For initial experiments using synthetic carboxylic acids, approximately $2 \mathrm{mg}$ of each standard was used. $\alpha$-Ketoglutaric acid (TCI America, Portland, OR), citric acid (Fisher Scientific, Pittsburg, PA), DL-malic acid (Aldrich, St Louis, MO) and succinic acid (J.T. Baker Co., Center Valley, PA) were used as representatives in each case. The identity of methyl esters generated using the methods described here was determined by comparison to the National Institute of Standards and Technology (NIST) spectral library and also to authentic commercially-available standards of dimethyl $\alpha$-ketoglutarate (Aldrich), trimethyl citrate (TCI), dimethyl DL-malate (TCI) and dimethyl succinate (TCI). In later experiments the more promising procedures were tested on more physiologically-realistic amounts (between 10 and $500 \mu \mathrm{g}$ ) of these four acids and two additional acids (fumaric acid and $\alpha$-hydroxyglutaric acid). For determination of endogenous levels of six TCA-cycle intermediates in duckweed, the following internal standards (all obtained from Sigma-Aldrich Isotec, St Louis, MO) were used: $\left[1,2,3,4-{ }^{13} \mathrm{C}_{4}\right] \alpha$-ketoglutaric acid (99 atom \%), $\left[2,4-{ }^{13} \mathrm{C}_{2}\right]$ citric acid (99 atom \%), $\left[{ }^{13} \mathrm{C}_{4}\right]$ fumaric acid (99 atom \%), [2,3,3-

$\left.{ }^{2} \mathrm{H}_{3}\right]$ DL-malic acid (98 atom \%) and $\left[{ }^{2} \mathrm{H}_{6}\right]$ succinic acid (98 atom \%). In all experiments, internal standard solutions with the concentrations shown in Table 1 were used. For reduction of unstable acids, $\mathrm{NaB}^{2} \mathrm{H}_{3} \mathrm{CN}$ (Aldrich) was used. 


\subsection{GC-MS}

For GC-MS analyses two systems were used. The first consisted of an Agilent 6890 GC coupled to an Agilent 5973 single quadrupole MS; the second consisted of an HP5890 Series II GC coupled to an HP5970 single quadrupole MS. The following description of conditions applies to both systems. The injector was held at $230^{\circ} \mathrm{C}$ and the injection volume was $1 \mu \mathrm{L}$. Initially three stationary phases were tested for appropriateness for the analytes of interest; these were $50 \%$ Phenyl 50\% dimethyl arylene siloxane (Agilent DB-17MS), 5\% Phenyl 95\% dimethylpolysiloxane (Phenomenex Zobron ZB-5) and 50\% Cyanopropyl-phenyl 50\% dimethyl polysiloxane (Agilent DB-225MS). For the vast majority of the analyses, an Agilent DB-225MS column (length $=30 \mathrm{~m}, \mathrm{ID}=0.25 \mathrm{~mm}$, film thickness $=0.25 \mu \mathrm{m}$ ) was used with He as the carrier gas at a constant flow rate of $1.0 \mathrm{~mL} / \mathrm{min}$. For all GC-MS analyses, the following temperature gradient was used: held at $50{ }^{\circ} \mathrm{C}$ for $2 \mathrm{~min}$, increased at $50{ }^{\circ} \mathrm{C} / \mathrm{min}$ to $100{ }^{\circ} \mathrm{C}$, increased at $25^{\circ} \mathrm{C} / \mathrm{min}$ to $230^{\circ} \mathrm{C}$ and finally held for $2.5 \mathrm{~min}$. For analysis of derivatization products using standards, full scan mode was used. All other analyses were conducted in selected ion monitoring (SIM) mode. The following $\mathrm{m} / \mathrm{z}$ values were monitored when the instrument was run in SIM mode: $86\left(\left[{ }^{2} \mathrm{H}_{1}\right]\right.$ dimethyl $\alpha$-hydroxyglutarate $), 89\left(\left[{ }^{13} \mathrm{C}_{4},{ }^{2} \mathrm{H}_{1}\right]\right.$ dimethyl $\alpha$ hydroxyglutarate), 103 (dimethyl malate), 104 ([ $\left.{ }^{2} \mathrm{H}_{1}\right]$ dimethyl malate), $106\left(\left[{ }^{2} \mathrm{H}_{3}\right]\right.$ dimethyl malate), 113 (dimethyl fumarate) 115 (dimethyl succinate; dimethyl $\alpha$-ketoglutarate), 117 ([ $\left[{ }^{13} \mathrm{C}_{4}\right]$ dimethyl fumarate), $119\left(\left[{ }^{2} \mathrm{H}_{4}\right]\right.$ dimethyl succinate; $\left[{ }^{2} \mathrm{H}_{6}\right]$ dimethyl $\alpha$-ketoglutarate $), 143$ (trimethyl citrate), $145\left(\left[{ }^{13} \mathrm{C}_{2}\right]\right.$ trimethyl citrate). For analyses on the Agilent system, each ion was monitored for the entire run and had a dwell time of $5 \mathrm{~ms}$; for analyses on the HP system, the 
ions were monitored in three separate windows (4.5-6.5 min: 113, 115, 117, 119; 6.5-8.5 min: $86,89,103,104,106,115,118 ; 8.5-9.7 \mathrm{~min}: 143,145)$ and each ion had a dwell time of $10 \mathrm{~ms}$.

\subsection{Methylation}

\subsubsection{Methanolic HCl}

This method was adapted from [11]. Citric acid was weighed into a vial and dissolved in anhydrous methanol (500 $\mu \mathrm{L}$; Sigma-Aldrich, St Louis, MO). The resulting solution was chilled on ice and acetyl chloride (50 $\mu \mathrm{L}$; Sigma-Aldrich) was added drop-wise to the mixture to generate a citric acid solution in methanolic $\mathrm{HCl}$. The reaction mixture was then heated in a sealed vial and held at $100{ }^{\circ} \mathrm{C}$ for $1 \mathrm{~h}$, after which it was allowed to cool to room temperature before the reaction was quenched with aqueous $\mathrm{K}_{2} \mathrm{CO}_{3}(1000 \mu \mathrm{L} ; 6 \% \mathrm{v} / \mathrm{v})$ and extracted into $\mathrm{CHCl}_{3}\left(500 \mu \mathrm{L}\right.$; Sigma-Aldrich). An aliquot $(10 \mu \mathrm{L})$ of the $\mathrm{CHCl}_{3}$ layer was diluted to $50 \mu \mathrm{L}$ with $\mathrm{CHCl}_{3}$ and then analyzed by GC-MS. The procedure outlined above was repeated with the three remaining representative carboxylic acids and also with fumaric acid.

When this method was applied to low-concentration standards or plant extracts post-reduction of unstable acids (see below), the following modified method was used. Anhydrous methanol $(100 \mu \mathrm{L})$ was added to the dry residue from the solution or extract and the resulting solution was chilled on ice. Acetyl chloride $(10 \mu \mathrm{L})$ was slowly added to the mixture, which was then heated in a sealed vial and held at $100{ }^{\circ} \mathrm{C}$ for $1 \mathrm{~h}$. After it was allowed to cool to room temperature, aqueous $\mathrm{NaHCO}_{3}(350 \mu \mathrm{L} ; 500 \mathrm{mM})$ and $\mathrm{CHCl}_{3}(60 \mu \mathrm{L}$; Sigma-Aldrich) were added and the resulting mixture was vortexed for approximately $10 \mathrm{~s}$. The entire mixture was then transferred 
to a disposable culture tube (Fisherbrand, 6 x $50 \mathrm{~mm}$ lime glass) and centrifuged (1000 $\mathrm{g}$ for $30 \mathrm{~s})$ to aid in phase separation. A portion $(40 \mu \mathrm{L})$ of the organic phase was taken for GC-MS analysis.

\subsubsection{Methanolic $\mathrm{H}_{2} \mathrm{SO}_{4}$}

The method was adapted from [12]. Citric acid was weighed into a vial and dissolved in anhydrous methanol $(500 \mu \mathrm{L})$. The resulting solution was chilled on ice and concentrated $\mathrm{H}_{2} \mathrm{SO}_{4}$ (two drops; Fisher Scientific) was added and the resulting mixture was heated in a sealed vial and held at $100{ }^{\circ} \mathrm{C}$ for $1 \mathrm{~h}$. After cooling to room temperature, $\mathrm{CHCl}_{3}(500 \mu \mathrm{L})$ and $\mathrm{H}_{2} \mathrm{O}$ $(1000 \mu \mathrm{L})$ were added to the reaction mixture. An aliquot $(10 \mu \mathrm{L})$ of the $\mathrm{CHCl}_{3}$ layer was diluted to $50 \mu \mathrm{L}$ with $\mathrm{CHCl}_{3}$ and then analyzed by GC-MS. The procedure outlined above was repeated with the three remaining representative carboxylic acids.

\subsubsection{Ethereal diazomethane}

Citric acid was weighed into a vial and dissolved in anhydrous methanol (400 $\mu \mathrm{L})$. Ethereal diazomethane $(1500 \mu \mathrm{L})$, generated as described in [13] was added and the resulting mixture was left at room temperature for $30 \mathrm{~min}$. The solvent was then evaporated under $\mathrm{N}_{2}$, and the residue was then redissolved in $\mathrm{CHCl}_{3}(500 \mu \mathrm{L})$. An aliquot $(10 \mu \mathrm{L})$ of the solution was diluted to $50 \mu \mathrm{L}$ with $\mathrm{CHCl}_{3}$ and then analyzed by GC-MS. The above experiment was repeated but the reactions were left for $22 \mathrm{~h}$ at room temperature. Both procedures outlined above were repeated with the three remaining representative carboxylic acids. 


\subsubsection{Ethereal (TMS)diazomethane}

The method was adapted from [14], [15] and [16]. Citric acid was dissolved in $400 \mu \mathrm{L}$ of methanol and $1500 \mu \mathrm{L}$ of (TMS)diazomethane (Acros Organics, Geel, Belgium; 0.2 M in 9:1 diethyl ether/hexanes). The resulting mixture was vigorously shaken, after which the vial cap was loosened, and the reaction allowed to proceed at room temperature for $30 \mathrm{~min}$, after which the solvents were evaporated under $\mathrm{N}_{2}$, and the residue dissolved in $\mathrm{CHCl}_{3}(500 \mu \mathrm{L})$. Aliquots $(10 \mu \mathrm{L})$ of the resulting solution was diluted to $50 \mu \mathrm{L}$ with $\mathrm{CHCl}_{3}$ and analyzed by GC-MS. The procedure outlined above was repeated with the three remaining representative carboxylic acids.

\subsubsection{Tin (II) chloride}

This method was adapted from [17]. Citric acid was weighed into a vial and dissolved in anhydrous methanol $(500 \mu \mathrm{L})$, along with $\sim 1 \mathrm{mg}$ of $\mathrm{SnCl}_{2}$ (Sigma). The resulting mixture was heated and held at $100{ }^{\circ} \mathrm{C}$ for $20 \mathrm{~h}$. After cooling to room temperature, the solvent was evaporated under $\mathrm{N}_{2}$, and the residue was then redissolved in $\mathrm{CHCl}_{3}(500 \mu \mathrm{L})$. An aliquot $(10 \mu \mathrm{L})$ of the solution was diluted to $50 \mu \mathrm{L}$ with $\mathrm{CHCl}_{3}$ and then analyzed by GC-MS. The procedure outlined above was repeated with the three remaining representative carboxylic acids.

\subsection{Development and evaluation of the extraction, reduction and purification method}

A suitable extraction and purification method for carboxylic acids was determined using synthetic commercially-available standards of the four representative acids listed in section 2.1. Methanol/water (4:1) was chosen as the extraction solvent for two reasons: 1 ) methanol is known 
to be a good extraction solvent for many organic compounds, 2) methanol aids in the denaturation of enzymes that may cause reaction of metabolites of interest, which would interfere with accurate quantification. Strong anion exchange (SAX) solid phase extraction (SPE) was chosen to provide a relatively simple and convenient means of separating base-ionizable compounds from the other components of the extract. The columns chosen were Alltech ExtractClean SAX disposable SPE columns (100 mg; $1.5 \mathrm{~mL}$ ), which consist of tetramethyl ammonium functional groups on a styrene-divinylbenzene base (W.R. Grace, Columbia MD).

Some naturally-occurring carboxylic acids are somewhat labile. For example, oxaloacetic acid is a $\beta$-keto acid and TCA cycle intermediate that undergoes spontaneous decarboxylation to form pyruvate at temperatures above $0{ }^{\circ} \mathrm{C}$ (pure solutions at $\mathrm{pH} 5$ and $30{ }^{\circ} \mathrm{C}$ degrades at a rate of approximately $1 \%$ per minute; [18]). This compound was stabilized by reduction with $\mathrm{NaB}^{2} \mathrm{H}_{3} \mathrm{CN}$, using a method adapted from [19]. $\mathrm{NaB}^{2} \mathrm{H}_{3} \mathrm{CN}$ was chosen over $\mathrm{NaB}^{2} \mathrm{H}_{4}$, because of its suitability for lower $\mathrm{pH}$ values. If the $\mathrm{pH}$ of a plant extract is raised too high (as it would be if $\mathrm{NaB}^{2} \mathrm{H}_{4}$ were used) one risks hydrolyzing naturally-occurring methyl esters, which would result in an overestimation of the free acid content using this method. The only major drawback of $\mathrm{NaB}^{2} \mathrm{H}_{3} \mathrm{CN}$ compared to $\mathrm{NaB}^{2} \mathrm{H}_{4}$ is that in aqueous acid solutions, as it is during the reduction process, it will produce hydrogen cyanide gas [20], which is extremely toxic; therefore, all steps involving $\mathrm{NaB}^{2} \mathrm{H}_{3} \mathrm{CN}$ were carried out in a fume hood. A deuterated reductant was chosen because reduction of OAA will produce $\left[{ }^{2} \mathrm{H}_{1}\right]$ malic acid, which is distinguishable from naturallyoccurring malic acid by MS. It was expected that $\alpha$-ketoglutaric acid present in plant extracts would also undergo reduction to form $\left[{ }^{2} \mathrm{H}_{1}\right] \alpha$-hydroxyglutaric acid. We found that the reduced 
solution could be applied directly to the SAX SPE column and all the acids of interest could be recovered using the procedure described below.

$\alpha$-Ketoglutaric acid (5.5 mg), citric acid (4.4 mg), fumaric acid $(4.7 \mathrm{mg})$, malic acid (5.4 mg)

oxaloacetic acid (Acros Organics; $5.2 \mathrm{mg}$ ) and succinic acid $(4.6 \mathrm{mg}$ ) were dissolved in extraction solvent $(5 \mathrm{~mL})$ and the resulting solution was diluted 1 in 100 . To $1 \mathrm{~mL}$ of this solution was added $\mathrm{NaB}^{2} \mathrm{H}_{3} \mathrm{CN}(30 \mathrm{mg} / \mathrm{mL}$ in $10-\mathrm{mM}$ acetate buffer, $\mathrm{pH} 3.69,100 \mu \mathrm{L})$, followed by acetic acid $(1 \mathrm{M}, 75 \mu \mathrm{L})$; the resulting mixture was stirred at room temperature for $90 \mathrm{~min}$ and then neutralized with $\mathrm{KOH}(20 \mathrm{mM}, 5.00 \mathrm{~mL}$; the $\mathrm{pH}$ of the resulting mixture was 6.78) so that the carboxylic acids were deprotonated $\left(\mathrm{pK}_{\mathrm{a}}\right.$ values: $\alpha$-ketoglutaric acid $=2.5,4.7$; citric $\operatorname{acid}=3.1,4.8,6.4 ;$ fumaric acid $=3.0,4.4 ;$ malic acid $=3.4,5.1 ;$ oxaloacetic acid = 2.2, 3.9; succinic acid $=4.2,5.6$ ). During the following procedure, the flow-rate through the SPE column was kept at approximately $3 \mathrm{~mL} / \mathrm{min}$. The $\mathrm{SAX} \mathrm{SPE}$ column was pre-conditioned with $\mathrm{CH}_{3} \mathrm{OH}$ ( $1 \mathrm{~mL}$; to remove phthalates and other plasticizers, which can interfere with GC-MS analysis) followed by $\mathrm{H}_{2} \mathrm{O}(3 \mathrm{~mL})$. The sample mixture was then applied to the column and 4:1 $\mathrm{CH}_{3} \mathrm{OH} / \mathrm{H}_{2} \mathrm{O}$ was used as the washing solvent, to remove any unbound compounds. Several combinations of $\mathrm{CH}_{3} \mathrm{OH}$, formic acid, $\mathrm{H}_{2} \mathrm{O}$ and $\mathrm{HCl}$ were tested to find a suitably polar elution solvent capable of lowering the $\mathrm{pH}$ enough to protonate and elute all the acids of interest. The most effective combination was found to be $1 \mathrm{M} \mathrm{HCl}$ in $1: 1 \mathrm{MeOH} / \mathrm{H}_{2} \mathrm{O}(8 \mathrm{~mL})$.

The liquid was evaporated under reduced pressure and anhydrous methanol $(100 \mu \mathrm{L})$ was added to the residue on ice. Acetyl chloride $(10 \mu \mathrm{L})$ was then added, after which the vial was sealed, vortexed for approximately $10 \mathrm{~s}$ and held at $100{ }^{\circ} \mathrm{C}$ for $60 \mathrm{~min}$. After cooling, $\mathrm{NaHCO}_{3}$ 
$(500 \mathrm{mM} ; 350 \mu \mathrm{L})$ and chloroform $(60 \mu \mathrm{L})$ were added to the mixture. The mixture was vortexed for approximately $10 \mathrm{~s}$ before being transferred to a micro test tube and centrifuged (30 s at $1000 \mathrm{~g}$ ) to aid in phase separation. The organic phase $(40 \mu \mathrm{L})$ was taken for GC-MS analysis as described in section 2.2 .

\subsection{Quantifying short-chain carboxylic acids from greater duckweed}

The method outlined in section 2.4 was applied to an extract from greater duckweed, grown on sterile liquid SH media (prepared from Schenk and Hildebrandt Basal Salt Mixture from SigmaAldrich, according to the manufacturer's instructions) from two clonal four-frond colonies for approximately four weeks, under a $16 / 8$ day/night cycle of white light $\left(75 \mu \mathrm{mol} / \mathrm{m}^{-2} \mathrm{~s}^{-1} 1\right)$ at $22{ }^{\circ} \mathrm{C}$. The procedure described below was repeated on numerous duckweed samples with fresh weights ranging from $0.5 \mathrm{mg}$ to $293 \mathrm{mg}$. Colonies were removed from the medium, blotted dry on paper towel, dissected using forceps if required, and placed into pre-weighed screw-cap microcentrifuge tubes (USA Scientific, Ocala, FL; polypropylene). The tubes were re-weighed to obtain the fresh weight, snap frozen in liquid $\mathrm{N}_{2}$ and stored at $-80{ }^{\circ} \mathrm{C}$ until needed. Pre-chilled $\left(-20^{\circ} \mathrm{C}\right) 4: 1 \mathrm{CH}_{3} \mathrm{OH} / \mathrm{H}_{2} \mathrm{O}(1000 \mu \mathrm{L})$ was added to each sample along with internal standard mixture $\left(10 \mu \mathrm{L}\right.$; containing $\left[{ }^{2} \mathrm{H}_{6}\right]$ succinic, $\left[{ }^{2} \mathrm{H}_{3}\right]$ malic, $\left[{ }^{13} \mathrm{C}_{4}\right] \alpha$-ketoglutaric, $\left[{ }^{13} \mathrm{C}_{4}\right]$ fumaric and $\left[{ }^{13} \mathrm{C}_{2}\right]$ citric acids in extraction solvent). Two steel beads (Alfa Aesar, Ward Hill, MA; $3 \mathrm{~mm}$ ) were added to the tubes and the plant material was pulverized using a tissue homogenizer (SPEX SamplePrep Geno/Grinder; 1750 rpm for 5 min; the metal sample block was pre-chilled to $20^{\circ} \mathrm{C}$ ) and held overnight at $-80{ }^{\circ} \mathrm{C}$. The samples were then vortexed for $10 \mathrm{~min}$ at room temperature and centrifuged at $2.5 \times 10^{4} \mathrm{rpm}$ at $4{ }^{\circ} \mathrm{C}$ for $10 \mathrm{~min}$. After this the samples were 
either reduced with $\mathrm{NaB}^{2} \mathrm{H}_{3} \mathrm{CN}$ (as in section 2.4, except $100 \mu \mathrm{L}$ of 1-M acetic acid was added instead of $75 \mu \mathrm{L}$ and more $\mathrm{KOH}$ was required at the neutralization step for some of the higher fresh weight samples) and then purified, derivatized and analyzed accordingly, or were diluted with imidazole. $\mathrm{HCl}$ buffer $(10 \mathrm{mM}, \mathrm{pH} 7.33)$ until the $\mathrm{pH}$ was between than 6.5 and 7.5 , loaded onto SAX cartridges (Alltech, $100 \mathrm{mg}, 1.5 \mathrm{~mL}$ ) and purified using the method described in section 2.4. We compared two methylation procedures for use on plant extracts that had been purified using the procedure outlined in section 2.4: methanolic $\mathrm{HCl}$ and ethereal (TMS)diazomethane. Equation 1 was used for absolute quantification.

$$
l=\left(A_{U} \cdot m_{I S}\right) /\left(A_{I S} \cdot F W\right)(\text { Equation } 1)
$$

where $l$ is the analyte level in $\mathrm{ng} / \mathrm{mg}(\mathrm{FW}), A_{U}$ is the peak area for endogenous analyte ion, $m_{I S}$ is the mass of internal standard added to extract, $A_{I S}$ is the peak area for internal standard ion and $F W$ is the fresh weight. Any small contribution of the internal standard to the endogenous peak area or vice versa was corrected for prior to calculating the level of each analyte. These correction factors were determined by running each of the internal standards and unlabeled standards separately. For malic and oxaloacetic acids, the following corrections were applied to account for overlap of the isotopic envelope for dimethyl malate, $\left[{ }^{2} \mathrm{H}_{1}\right]$ dimethyl malate and $\left[{ }^{2} \mathrm{H}_{3}\right]$ dimethyl malate:

$$
\begin{gathered}
z=(100 a-9300 c-3 / 17(100 b-600 c)) \cdot-17 / 142180(\text { Equation } 2) \\
y=\frac{100 b-600 c+541 z}{85}(\text { Equation } 3) \\
x=100 c-91 z(\text { Equation } 4)
\end{gathered}
$$


where $a, b$ and $c$ are the observed peak areas for $m / z$ 103, 104 and 106 and $x, y$ and $z$ are the corrected peak areas for these ions.

\subsection{Interrogation and modification of the method}

\subsubsection{Limit of detection/Limit of quantification}

Equation 5 was used to calculate the limit of detection of the GC-MS method.

$$
L O D=\bar{x}_{\text {blank }}+S D_{\text {blank }}(\text { Equation } 5)
$$

Where LOD is the 'limit of detection', $\bar{x}_{\text {blank }}$ is the mean detector response for a selected ion of interest at the relevant retention time and $S D_{\text {blank }}$ is the standard deviation of the signal for the blank $(n=4)$. This gives an LOD in arbitrary units, which was converted to nmol on column through linear regression of serial dilutions of each of the representative methyl ester standards.

For LOD/LOQ calculations on the HP GC-MS system, the serial dilutions of commerciallyavailable standards were prepared as follows: Dimethyl- $\alpha$-ketoglutarate $(8.31 \mu \mathrm{L})$, dimethyl malate $(8.06 \mu \mathrm{L})$, dimethyl succinate $(9.55 \mu \mathrm{L})$ and trimethyl citrate $(11.61 \mathrm{mg})$ were each dissolved in chloroform $(25 \mathrm{~mL})$ using volumetric glassware. Each one of the resulting solutions was used to prepare a serial dilution (consisting of $2 \mathrm{x}, 4 \mathrm{x}, 8 \mathrm{x}, 16 \mathrm{x}, 32 \mathrm{x}, 64 \mathrm{x}$ and 128x dilutions) all of which were analyzed in triplicate using the HP GC-MS system.

\subsubsection{Recovery from SAX SPE}

To determine the recovery from the SAX SPE columns, the following experiment was performed. $\alpha$-Ketoglutaric acid (5.5 mg), citric acid (4.4 mg), fumaric acid (4.7 mg), malic acid $(5.4 \mathrm{mg}$ ) oxaloacetic acid (Acros Organics; $5.2 \mathrm{mg}$ ) and succinic acid (4.6 mg) were dissolved in 
4:1 $\mathrm{MeOH} / \mathrm{H}_{2} \mathrm{O}$ and the resulting solution was diluted 1 in 100 . This mixture was reduced with $\mathrm{NaBCN}^{2} \mathrm{H}_{3}$ and purified by SAX SPE as described in section 2.4. To the dry residue was added the internal standard mixture $(10 \mu \mathrm{L})$ and the liquid was evaporated under a gentle stream of $\mathrm{N}_{2}$. This sample was then methylated using methanolic $\mathrm{HCl}$ and analyzed using the HP GC-MS system, as described in section 2.2. Equation 6 was used to calculate the apparent percent recovery for each acid.

$$
r=\left[\frac{A_{U} / A_{I S}}{m_{U} / m_{I S}}\right] .100 \text { (Equation 6) }
$$

Where $r$ is the percent recovery $A_{U}$ is the peak area for the unlabeled compound, $A_{I S}$ is the peak area for the internal standard, $m_{U}$ is the mass of unlabeled material in the mixture and $m_{I S}$ is the mass of internal standard added to the mixture.

\subsubsection{Reproducibility of the method}

To assess its reproducibility, the method described in 2.5 was performed using two groups, each consisting of three duckweed samples of similar fresh weight ('High fresh weight' group: 95, 122 and $120 \mathrm{mg}$; 'Low fresh weight' group: 40, 51 and $61 \mathrm{mg}$ ).

\section{Results}

\subsection{Evaluation of derivatization methods}

The five derivatization methods examined here displayed varying yields when applied to carboxylic acid standards (see Figures 1-5 and Figure 6B for mass spectra of methyl esters produced using methylation methods described here). Methanolic $\mathrm{HCl}$ and methanolic $\mathrm{H}_{2} \mathrm{SO}_{4}$ 
yielded similar results. Trimethyl citrate, dimethyl malate and dimethyl succinate were produced, with very few detectable artifacts or by-products. However, the most abundant product detected by GC-MS when $\alpha$-ketoglutaric acid was used had a mass fragmentation pattern consistent with bis-(methoxycarbonyl)-ethoxyiminomethane (according to the NIST library; see Figure 6 and Figure S1A). We attribute this undesirable conversion to the low $\mathrm{pH}$ values and high temperature used in these methods. Even at lower temperatures, substantial conversion to this product was observed. In contrast to acidic methanol, ethereal diazomethane was a fairly ineffective reagent for all acids tested. Even after $22 \mathrm{~h}$, only a very small portion of $\alpha$-ketoglutaric acid was converted to dimethyl $\alpha$-ketoglutarate (calculated from the peak areas, the ratio of $\alpha$-ketoglutaric acid to dimethyl $\alpha$-ketoglutarate was approximately $31: 1$; data not shown). Trimethyl citrate and dimethyl malate were detected only at very low levels and dimethyl succinate was undetectable by GC-MS after $1 \mathrm{~h}$ and $22 \mathrm{~h}$. Monomethyl succinate was detected after $22 \mathrm{~h}$, but the dimethyl ester was below the limit of detection. (TMS)diazomethane and Tin (II) chloride reaction conditions supported the conversion of all four representative carboxylic acids to their respective methyl esters. However, when (TMS)diazomethane was used, a number of by-products were produced, including $O$-TMS-dimethylsuccinate from succinic acid. Furthermore, although the major product from $\alpha$-ketoglutaric acid detected by GC-MS was dimethyl $\alpha$-ketoglutarate, the methyl ester of the enol form of $\alpha$-ketoglutaric acid (dimethyl (2Z)-2-methoxypent-2-enedioate) was also detected at comparable levels. Similarly, derivatization with Tin (II) chloride resulted in formation of several byproducts, including dimethyl 3-methoxycarbonylpent-2-enedioate (Figure S1B), which is the dehydration product of citric acid. The biggest drawback for this method was the observed production of dimethyl succinate from $\alpha$-ketoglutaric acid; this observation by GC- 
MS makes this method essentially unsuitable for quantification of TCA cycle intermediates. Furthermore, as was observed using the acidic methanol methods described in sections 2.3 .1 and 2.3.2, significant production of a compound with a mass fragmentation pattern consistent with bis-(methoxycarbonyl)-ethoxyiminomethane (according to the NIST library matching) from $\alpha$ ketoglutaric acid was also observed using tin (II) chloride. Additionally, the tin (II) chloride method was the most time-consuming of the methods tested (by a factor of 40).

Five criteria were used to assess which of the methods was the best for analysis of short-chain carboxylic acids (see Table 2): reaction time, relative labor intensity, relative hazard level, relative number of by-products formed and whether or not conversion of all the representative acids to their respective methyl esters was observed. This assessment showed that methanolic $\mathrm{HCl}$ or $\mathrm{H}_{2} \mathrm{SO}_{4}$ was the most appropriate and efficient derivatization reagent. The methanolic $\mathrm{HCl}$ method was chosen for our analyses of plant extracts for two reasons: 1) the methanolic $\mathrm{HCl}$ method has a slightly easier set-up, and 2) $\mathrm{H}_{2} \mathrm{SO}_{4}$ is also an oxidant which has the potential to participate in more side-reactions; nevertheless, our experiments with standards indicated that both methods produce the methyl esters of all the acids tested.

\subsection{Evaluation of extraction, reduction and purification and derivatization methods when applied to biological samples}

Two of the methylation method showed potential for application to biological samples:

(TMS)diazomethane for its relatively mild conditions and methanolic $\mathrm{HCl}$ for its limited number of by-products. Both of these were applied to extracts of duckweed, which had been purified using the SAX SPE protocol. The two methods produced dramatically different chromatograms 
(Figure 7). The methanolic $\mathrm{HCl}$ method produced a very clean selected ion chromatogram (SIC) displaying the selected ions for all five methyl esters of interest. Conversely, the chromatogram produced by the ethereal (TMS)diazomethane method contained a large number contaminating peaks, which sometimes obscured the compounds of interest. Furthermore, the methyl esters of the acids of interest were sometimes absent from the chromatogram altogether. This is most likely due to the instability of ethereal (TMS)diazomethane in acidic solutions. Although the derivatization reagent was not applied until after evaporation of the acidic eluent, the residual $\mathrm{HCl}$ was found to consume much of the reagent (as evidenced by vigorous bubbling and loss of the green color associated with (TMS)diazomethane solutions), which often led to complete absence of methyl esters of the acids of interest when analyzed by GC-MS.

For quantification of the six acids, the minimum amount of tissue required was approximately $2 \mathrm{mg}$. Below this amount, the endogenous ion for one or more of the acids was below the LOQ or could not be detected at all (see Table 3). Above approximately $100 \mathrm{mg}$, we suspect that the extraction solvent becomes saturated, leading to gross underestimation of the endogenous content. Based upon these results we recommend using this method with 2-100 mg of tissue. Outside of this range, the MS signals may not be reliable, which will lead to erroneous conclusions.

\subsection{Evaluation of the analysis method}

Of the three stationary phases tested, 50\% cyanopropyl-phenyl 50\% dimethyl polysiloxane (Agilent DB-225MS) gave the best resolution and sharpest peaks for the analytes of interest. Dimethyl malate was the most problematic acid tested, giving an extensive tail on the other two 
stationary phases tested. The major drawback of the DB-225MS column was the instability of the stationary phase. After prolonged periods of idleness (more than one week), the peak for standard dimethyl malate would frequently begin tailing considerably (Figure S2). We hypothesize that this was due to degradation of the stationary phase, which changed it retention properties; this problem could be remedied by holding the column at the maximum isothermal temperature for six to eight hours (or overnight).

The limits of detection and quantification of our method were determined for each acid using the GC-MS system and are shown in Table 4 and the calibration curve for the four commerciallyavailable representative methyl esters is shown in (Figure 8). Although using the analysis method described in section 2.6.1 $\alpha$-ketoglutaric acid will be reduced to $\alpha$-hydroxyglutaric acid prior to methylation, it is reasonable to assume that the detector response for dimethyl $\alpha$ hydroxyglutarate would be similar to the response for dimethyl $\alpha$-ketoglutarate.

The apparent recovery from the SAX SPE column after reduction with $\mathrm{NaB}^{2} \mathrm{H}_{3} \mathrm{CN}$ was calculated for fumaric, succinic, malic and citric acids. These results are summarized in Table 5. The recovery of $\alpha$-ketoglutaric acid was not calculated, as the method employed did not allow calculation of this parameter.

The method was shown to be highly reproducible. Determinations of the six acids exhibited a high degree of similarity both within groups of similar fresh weights and between the two groups (Figure S3). While the samples within each group were of similar fresh weight, they contained tissues of different ages and at different developmental stages, which explains the variation 
between samples. Nevertheless, the observed variation in the determined levels is well within the expected range for biological replicates.

\section{Discussion}

In this series of experiments, several previously-published methylation methods were adapted for use with short-chain carboxylic acids [11-15]. Depending upon the analyte of interest, each of these methods may be used with varying yields expected. For analysis of TCA-cycle intermediates, we generally found methanolic $\mathrm{HCl}$ or (TMS)diazomethane to be the reagents giving the highest yields. Using these methods, the methyl esters of all of the carboxylic acids tested were produced. Furthermore, the reactions are quick and relatively easy to carry out. The main problem with the (TMS)diazomethane method is the large number of by-products formed. The Fischer esterification methods produced far fewer by-products, but led to the degradation of $\alpha$-ketoglutaric acid. However, we showed that this problem may be overcome by reduction with

$\mathrm{NaBCN}^{2} \mathrm{H}_{3}$, to produce $\alpha$-hydroxyglutaric acid, which may be derivatized using methanolic $\mathrm{HCl}$. By reducing the two labile acids of the TCA cycle (OAA and $\alpha$-ketoglutaric acid) and then applying the methanolic $\mathrm{HCl}$ derivatization method, we were able to quantify six of the TCA cycle intermediates by isotope dilution in a number of samples of duckweed of varying fresh weights. If detection of labile keto-acids are not required for a particular analysis, the reduction step may be omitted and the sample neutralized with imidazole $\cdot \mathrm{HCl}$ buffer, prior to loading it onto the SPE column (data not shown). The remainder of the procedure may then be conducted as detailed in section 2.4 . 
The yields of each of the methylation reactions tested were not fully determined. Still, even if some of these methods did not produce the desired methyl esters at $100 \%$ yield, this should not be detrimental when determining absolute metabolite levels if isotope dilution is used or analysis of heavy-isotope incorporation from feeding experiments involved in MFA. Assuming the labeled and unlabeled forms of the compound of interest behave identically during the extraction, purification, derivatization and analysis, the unlabeled:labeled ratio should not change throughout the analysis, thus allowing the two requisite parameters for MFA to be measured.

The extraction, purification, derivatization and analysis methods detailed here overcome several factors that may cause problems for analysis of short-chain carboxylic acids. First, using this method, naturally-occurring methyl esters in the plant extract are not hydrolysed by the relatively mild extraction and purification conditions used; this allows separation of free acids from esters by SAX SPE prior to derivatization for analysis by GC-MS, thus enabling determination of free acid content. Second, addition of methanol to the extraction solvent ensures denaturation of enzymes that could degrade free acids, thus removing another confounding factor. Third, snap freezing the tissue will effectively halt chemical reactions, thus giving an accurate 'snapshot' of metabolism at any given time point. Fourth, methylation provided significant advantages over trimethylsilylation for isotopic labeling experiments, as addition of two or three methyl groups introduces minimal disturbance to the isotopic envelope for a given compound. Fifth, use of a general extraction solvent mixture simplifies incorporation of this method into laboratory workflows. Taking into account the strengths of this method, it could be applied to a plethora of low-molecular-weight polar metabolites and used to answer many questions regarding the flux of pathways involving these metabolites. 


\section{Acknowledgements}

This research was funded by the National Science Foundation (IOS-1238812). We further acknowledge supplemental support from the Gordon and Margaret Bailey Endowment for Environmental Horticulture and the Minnesota Agricultural Experiment Station.

\section{$6 \quad$ References}

[1] J.H.F. Cavalcanti, A. Esteves-Ferreira, C. Quinhones, I. Pereira-Lima, A. Nunes-Nesi, A.R. Fernie, W. Araújo, Genome Biology and Evolution 6 (2014) 2830.

[2] L.J. Sweetlove, K.F.M. Beard, A. Nunes-Nesi, A.R. Fernie, R.G. Ratcliffe, Trends in Plant Science 15 (2010) 462.

[3] I. Hanning, H.W. Heldt, Plant Physiology 103 (1993) 1147.

[4] G. Tcherkez, A. Mahé, P. Gauthier, C. Mauve, E. Gout, R. Bligny, G. Cornic, M. Hodges, Plant Physiology 151 (2009) 620.

[5] N. Templeton, J. Dean, P. Reddy, J.D. Young, Biotechnology and Bioengineering 110 (2013) 2013.

[6] J. O'Grady, J. Schwender, Y. Shachar-Hill, J.A. Morgan, Journal of Experimental Botany 63 (2012) 2293.

[7] N.J. Kruger, S.K. Masakapalli, R.G. Ratcliffe, Journal of Experimental Botany 63 (2012) 2309. 
[8] Y. Gao, J. Yang, M. Cancilla, F. Meng, S. McLuckey, Analytical Chemistry 85 (2013) 4713.

[9] F.L. Estes, Analytical Chemistry 38 (1966) 1178.

[10] H. Luke, T. Freeman, L. Kier, Analytical Chemistry 35 (1963) 1916.

[11] J.T. Kodra, A.S. Jørgensen, B. Andersen, C. Behrens, C.L. Brand, I.T. Christensen, M. Guldbrandt, C.B. Jeppesen, L.B. Knudsen, P. Madsen, E. Nishimura, C. Sams, U.G. Sidelmann, R.A. Pedersen, F.C. Lynn, J. Lau, Journal of Medicinal Chemistry 51 (2008) 5387.

[12] E. Peuchant, R. Wolff, C. Salles, R. Jensen, Analytical Biochemistry 181 (1989) 341.

[13] J.D. Cohen, Journal of Chromatography A 303 (1984) 193.

[14] D.A. Rimmer, P.D. Johnson, R.H. Brown, Journal of Chromatography A 755 (1996) 245.

[15] L.J. Quittenden, N.W. Davies, J.A. Smith, P.P. Molesworth, N.D. Tivendale, J.J. Ross, Plant Physiology 151 (2009) 1130.

[16] N.D. Tivendale, N.W. Davies, P.P. Molesworth, S.E. Davidson, J.A. Smith, E.K. Lowe, J.B. Reid, J.J. Ross, Plant Physiology 154 (2010) 1957.

[17] C.S. Cho, D.T. Kim, H.J. Choi, T.J. Kim, S.C. Shim, Bulletin of the Korean Chemical Society 23 (2002) 539.

[18] M. Hatch, M. Tsuzuki, G. Edwards, Plant Physiology 69 (1982) 483.

[19] R.F. Borch, M.D. Bernstein, H.D. Durst, Journal of the American Chemical Society 93 (1971) 2897.

[20] C. Lane, Synthesis 1975 (1975) 135. 


\section{$7 \quad$ Figure Legends}

Figure 1 - Electron impact mass spectrum for $\left[{ }^{2} \mathrm{H}_{1}\right]$ dimethyl $\alpha$-hydroxyglutarate, produced by reduction with $\mathrm{NaB}^{2} \mathrm{H}_{3} \mathrm{CN}$ followed by methylation with methanolic $\mathrm{HCl}$ of an authentic standard of $\alpha$-ketoglutaric acid.

Figure 2 - Electron impact mass spectrum for trimethyl citrate.

Figure 3 - Electron impact mass spectrum for dimethyl fumarate.

Figure 4 - Electron impact mass spectrum for dimethyl malate.

Figure 5 - Electron impact mass spectrum for dimethyl succinate.

Figure 6 - (A) Total ion chromatogram produced when an authentic standard of $\alpha$-ketoglutaric acid was methylated using methanolic $\mathrm{HCl}$, along with electron impact mass spectra for the early- (B, $7.60 \mathrm{~min})$ and later- (C, $7.88 \mathrm{~min})$ eluting peaks.

Figure 7 - GC-MS Selected ion chromatogram (SIC) of a duckweed extract, purified by SAX SPE and methylated using methanolic $\mathrm{HCl}$ (A) or ethereal (TMS)diazomethane (B).

Figure 8 - Calibration plots for four representative short-chain methyl esters analyzed by GC-MS $(n=3)$. Equations for linear lines of best fit were calculated using the regression method in Microsoft Excel and peak areas were determined using the Agilent Chemstation integration tool. The equations for these lines are as follows: dimethyl $\alpha$-ketoglutarate: $y=4760.2 x+15912$ $\left(\mathrm{R}^{2}=0.99\right)$; trimethyl citrate: $y=-4.1576 x^{2}+10121 x+16309\left(\mathrm{R}^{2}=0.99\right)$; dimethyl malate: $y=3072.5 x+11132\left(\mathrm{R}^{2}=0.99\right)$; dimethyl succinate: $y=3563.8 x+8718$ 
$\left(\mathrm{R}^{2}=0.98\right)$. The detector response for trimethyl citrate appears to be linear at higher concentrations, but below approximately 100 pmol on column it is better modelled as a loworder polynomial. 
Table 1 - Internal standards and concentrations used in all experiments. Solutions were made up in $\mathrm{CH}_{3} \mathrm{OH}$.

\begin{tabular}{|l|l|}
\hline Internal standard & Concentration $(\mathrm{mM})$ \\
\hline$\left[{ }^{13} \mathrm{C}_{4}\right] \alpha$-ketogluaric acid & 1.757 \\
\hline$\left[{ }^{13} \mathrm{C}_{2}\right]$ citric acid & 1.373 \\
\hline$\left[{ }^{13} \mathrm{C}_{4}\right]$ fumaric acid & 2.344 \\
\hline$\left[2,3,3-{ }^{2} \mathrm{H}_{3}\right]$ DL-malic acid & 2.390 \\
\hline$\left[{ }^{2} \mathrm{H}_{6}\right]$ succinic acid & 3.11 \\
\hline
\end{tabular}


Table 2 - Various properties of five methylating agents, as determined using $\alpha$-ketoglutaric acid, citric acid, DL-malic acid and succinic acid as substrates, and analysing by GC-MS.

\begin{tabular}{|l|l|l|l|l|l|}
\hline Methylating reagent & $\begin{array}{l}\text { Reaction } \\
\text { time (h) }\end{array}$ & $\begin{array}{l}\text { Relative } \\
\text { labor } \\
\text { intensity }\end{array}$ & $\begin{array}{l}\text { Relative } \\
\text { hazard } \\
\text { level }\end{array}$ & $\begin{array}{l}\text { Relative } \\
\text { number of } \\
\text { by-products } \\
\text { formed }\end{array}$ & $\begin{array}{l}\text { Production of } \\
\text { methyl esters of } \\
\text { all representative } \\
\text { acids (Y/N)? }\end{array}$ \\
\hline Methanolic $\mathrm{HCl}$ & 1 & Moderate & Moderate & Few & Y \\
\hline Methanolic $\mathrm{H}_{2} \mathrm{SO}_{4}$ & 1 & Moderate & Moderate & Few & $\mathrm{Y}$ \\
\hline Diazomethane & 0.25 or 20 & High & High & Few & $\mathrm{N}$ \\
\hline (TMS)diazomethane & 0.5 & Very low & Moderate & Many & Y \\
\hline Tin (II) chloride & 40 & Low & Low & Few & Y \\
\hline
\end{tabular}


Table 3 - Quantification of six short-chain carboxylic acids from Spirodela polyrhiza, using GC-MS with isotope dilution. $\mathrm{ND}=$ Not detected.

\begin{tabular}{|l|l|l|l|l|l|l|l|}
\hline & \multirow{2}{*}{ Sample type } & \multicolumn{6}{|c|}{ Acid level (ng/mg (FW)) } \\
\cline { 3 - 9 } & $(\mathrm{mg})$ & Fumarate & Succinate & Malate & Oxaloacetate & $\alpha$-Ketoglutarate & Citrate \\
\hline One root & 0.5 & 161.0 & 750.0 & 572.4 & ND & ND & 354.9 \\
\hline One frond & 0.7 & 141.1 & 672.2 & 478.3 & 17.06 & ND & 636.0 \\
\hline Three roots & 0.8 & 66.60 & 696.0 & 504.7 & 43.52 & ND & 422.2 \\
\hline One colony & 1.9 & 118.3 & 492.0 & 2342 & 546.3 & 109.2 & 1871 \\
\hline Two large & 5.4 & 47.35 & 196.3 & 1128 & 133.8 & 40.74 & 899.7 \\
fronds & & & & & & & 1950 \\
\hline Five colonies & 40 & 13.05 & 130.3 & 1347 & ND & 30.88 & 1985 \\
\hline 10 colonies & 95 & 10.42 & 72.67 & 833 & 6.972 & 25.89 & \\
\hline
\end{tabular}


Table 4 - Measurements associated with the determination of the limit of detection and limit of quantification of a GC-MS method (performed using an HP GC-MS system) for methyl esters of short-chain carboxylic acids. Means and SDs are based on $n=4$.

\begin{tabular}{|c|c|c|c|c|c|c|c|}
\hline Acid & $\begin{array}{l}\text { Retention } \\
\text { interval } \\
(\min )\end{array}$ & $\begin{array}{l}\bar{x}_{\text {blank }} \\
\text { (arbitrary } \\
\text { units) }\end{array}$ & $\begin{array}{l}S D_{\text {blank }} \\
\text { (arbitrary } \\
\text { units) }\end{array}$ & $\begin{array}{l}\text { LOD } \\
\text { (arbitrary } \\
\text { units) }\end{array}$ & $\begin{array}{l}\text { LOQ } \\
\text { (arbitrary } \\
\text { units) }\end{array}$ & $\begin{array}{l}\text { LOD (pmol } \\
\text { on column) }\end{array}$ & $\begin{array}{l}\text { LOQ (pmol } \\
\text { on column) }\end{array}$ \\
\hline $\begin{array}{l}\text { Dimethyl- } \alpha \text { - } \\
\text { ketoglutarate }\end{array}$ & $7.56-7.64$ & 15912 & 672 & 17929 & 22635 & 0.42 & 1.41 \\
\hline Trimethylcitrate & $9.18-9.28$ & 16309 & 984 & 19261 & 26148 & 0.29 & 0.97 \\
\hline Dimethylmalate & $6.93-7.02$ & 11132 & 671 & 13146 & 17846 & 0.66 & 2.19 \\
\hline Dimethylsuccinate & $5.57-5.65$ & 8718 & 1080 & 11959 & 19520 & 0.91 & 3.03 \\
\hline
\end{tabular}


Table 5 - Apparent recovery of short-chain acids from SAX SPE column, as determined by GC-MS analysis.

\begin{tabular}{|l|l|}
\hline Acid & Recovery (\%) \\
\hline Fumaric & 91 \\
\hline Succinic & 81 \\
\hline Malic & 96 \\
\hline Citric & 107 \\
\hline
\end{tabular}




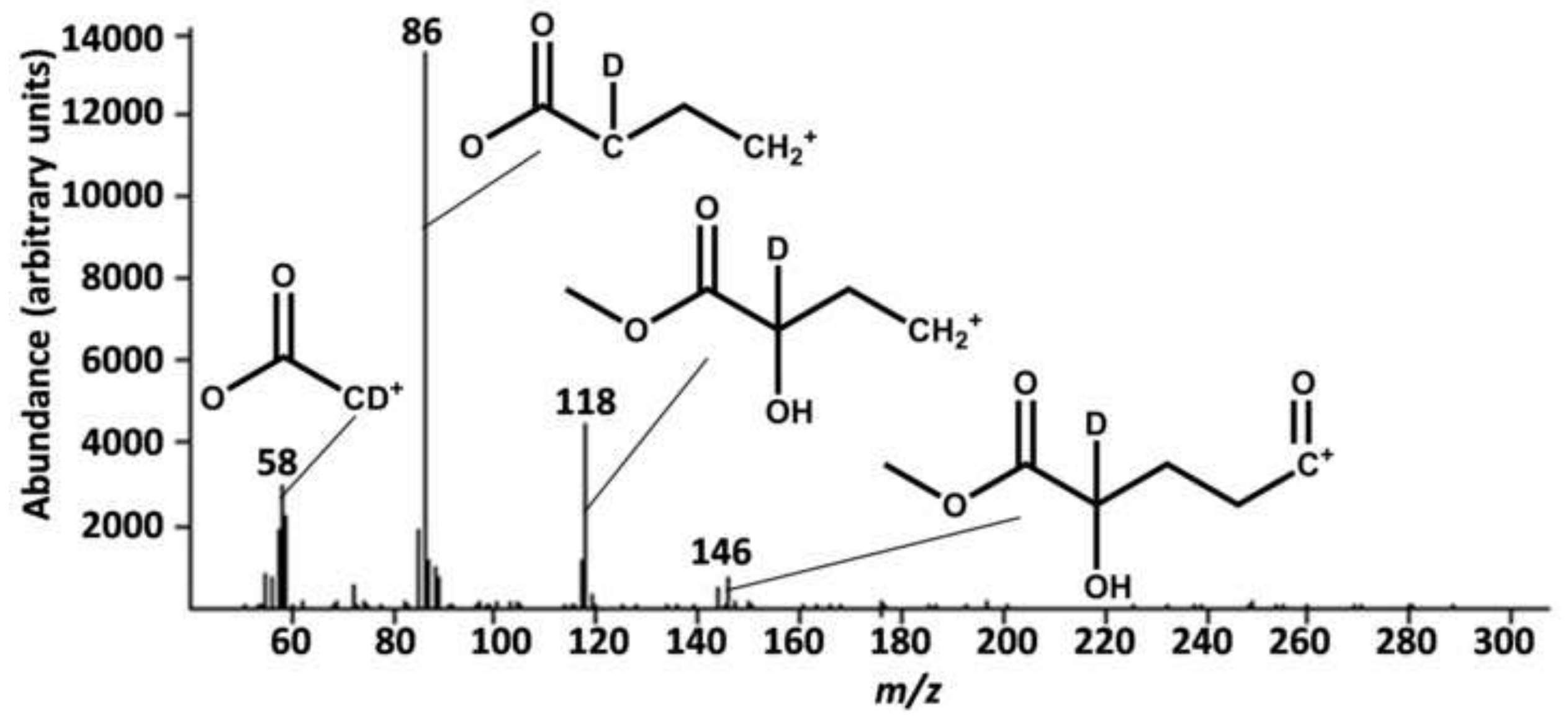




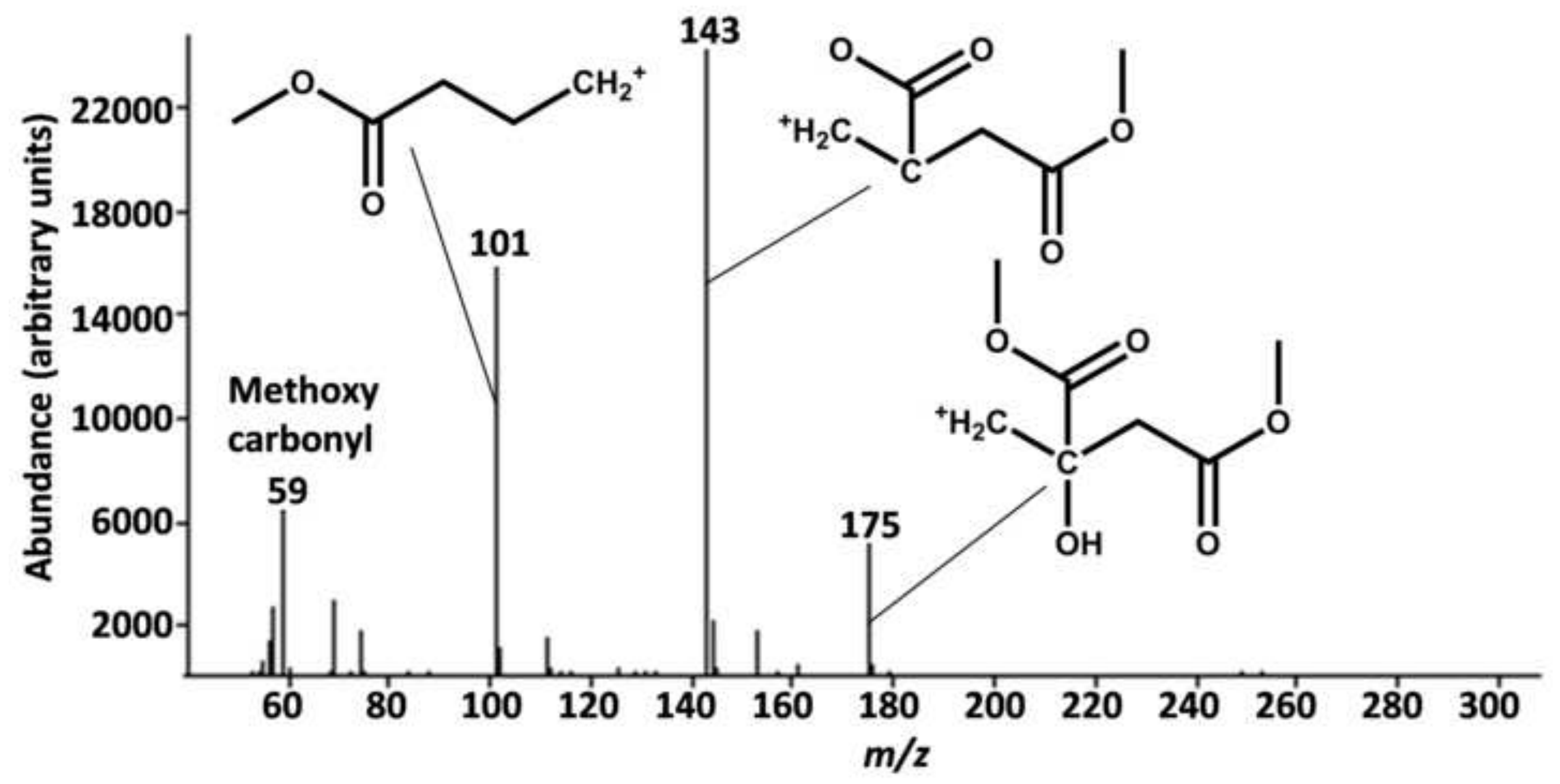




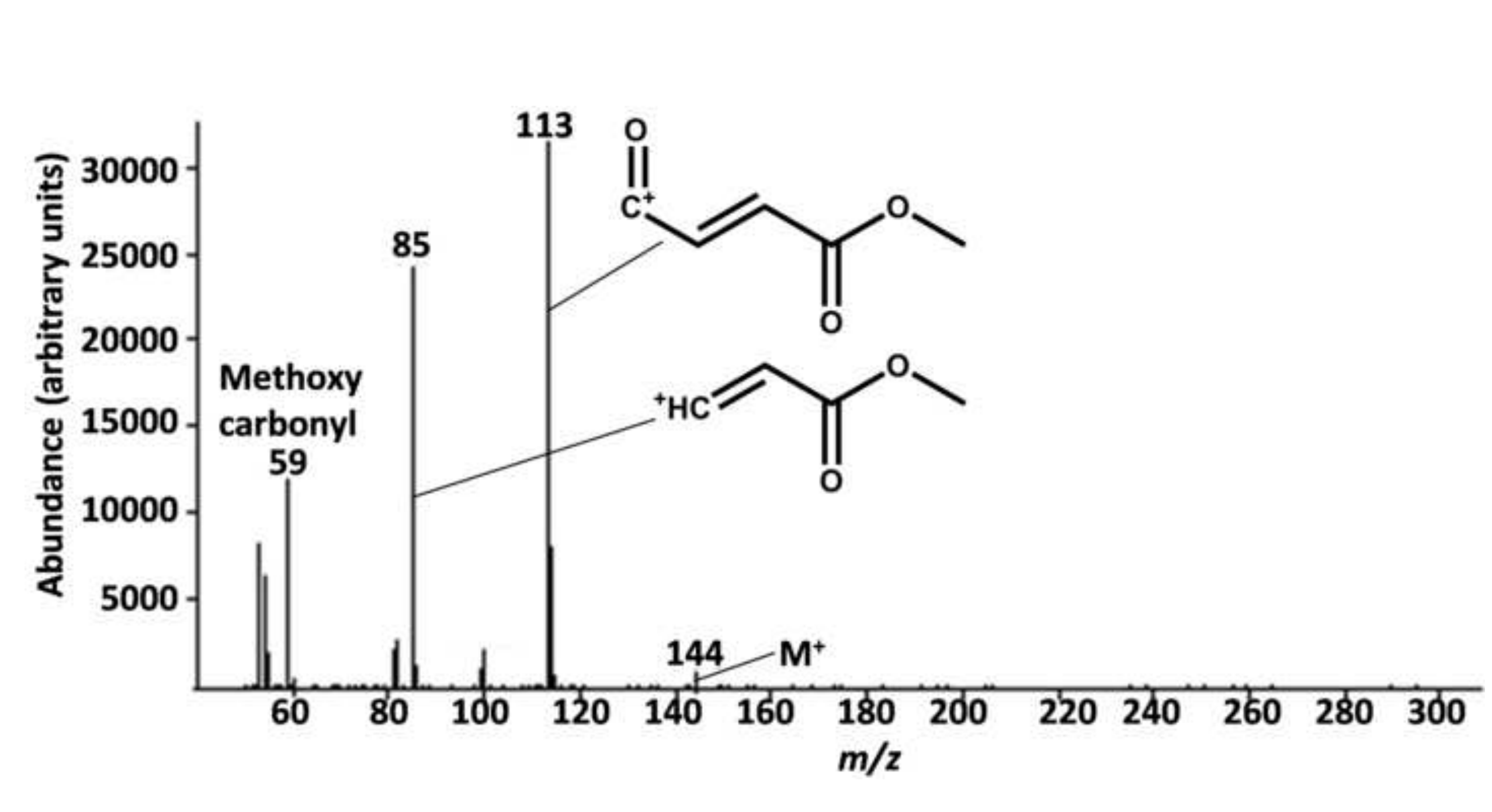

.
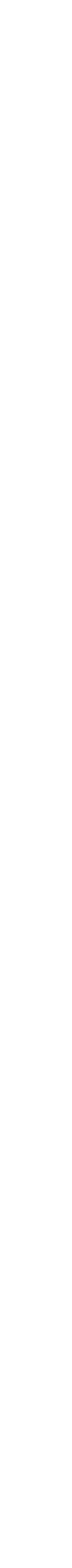

.

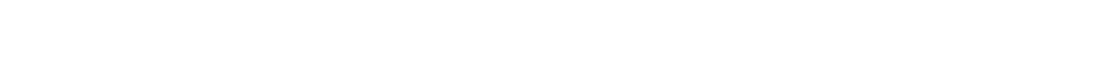




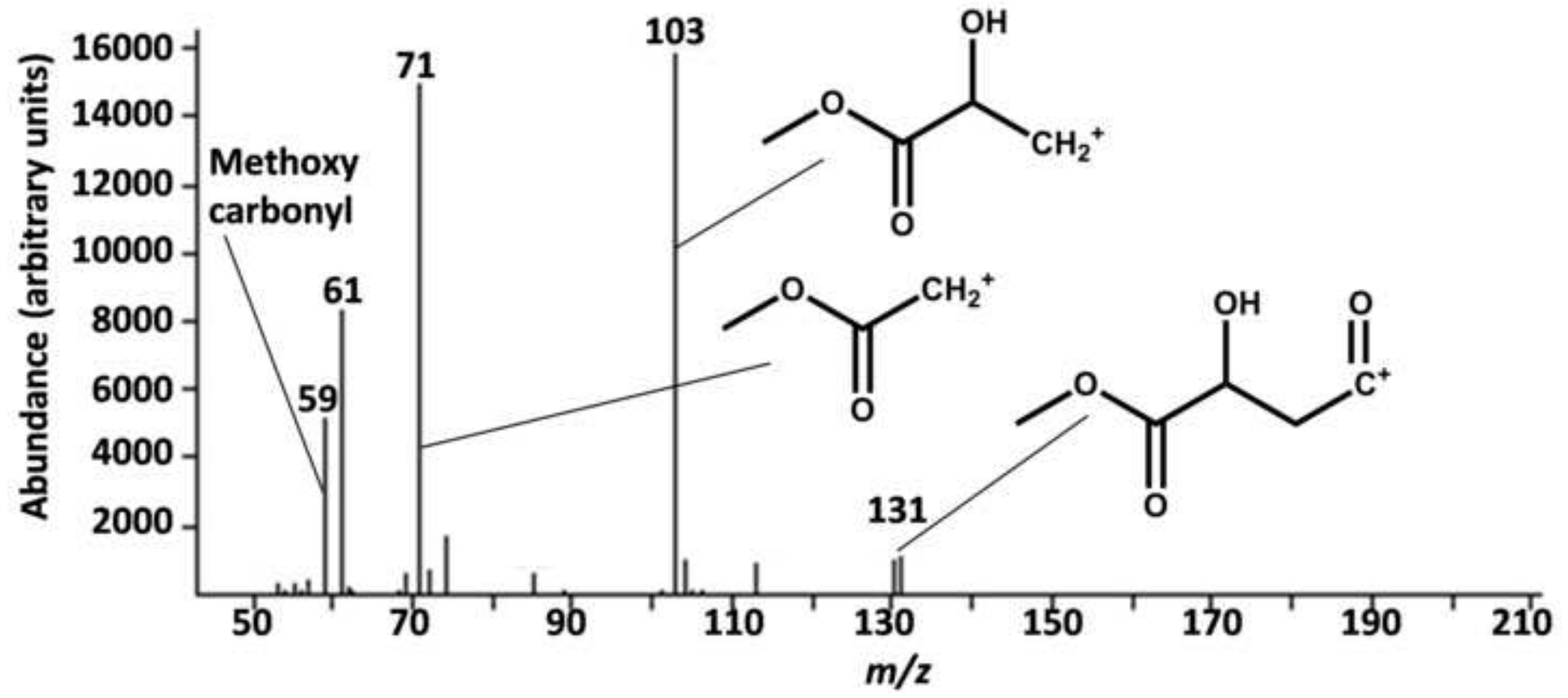




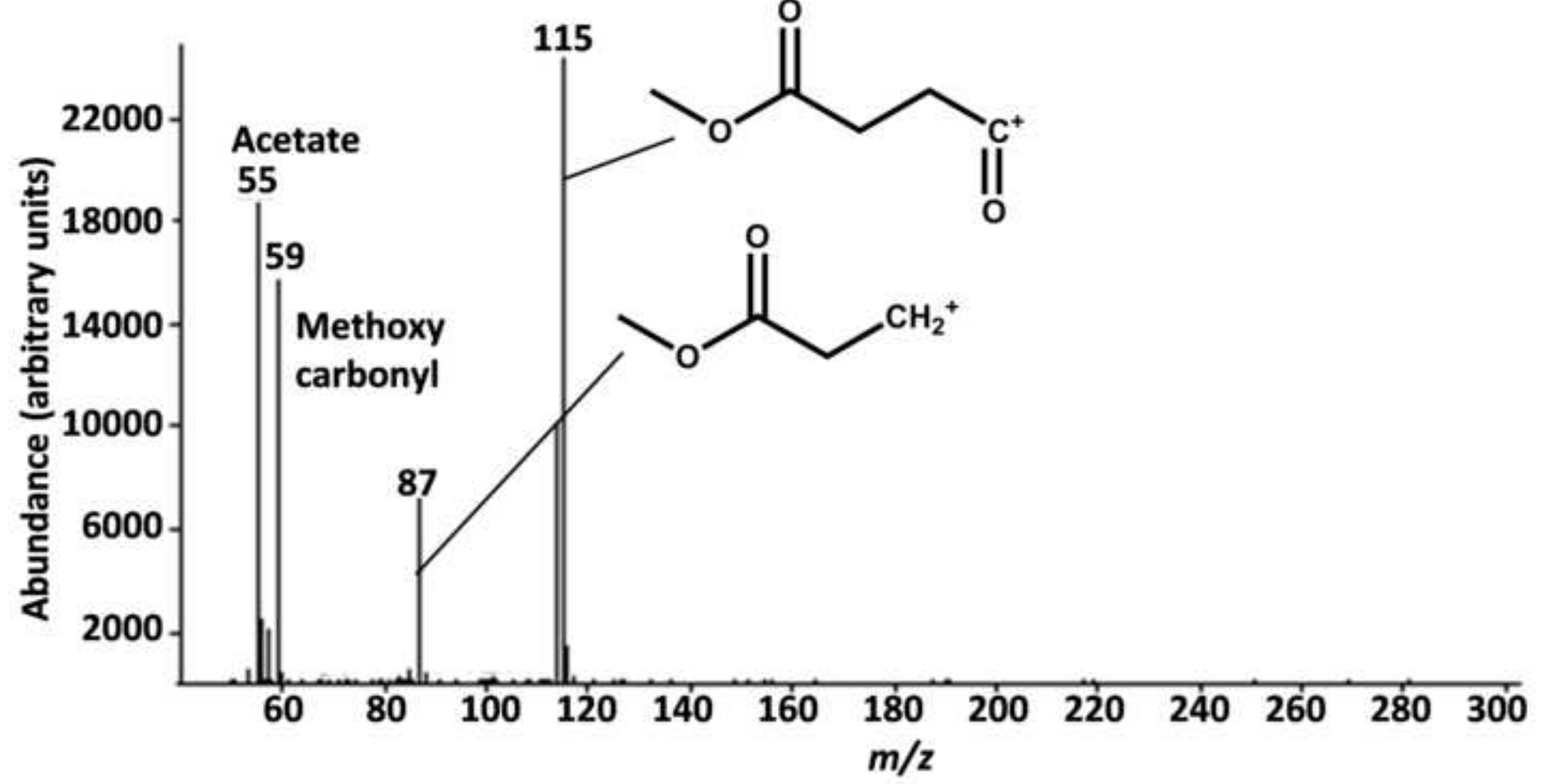



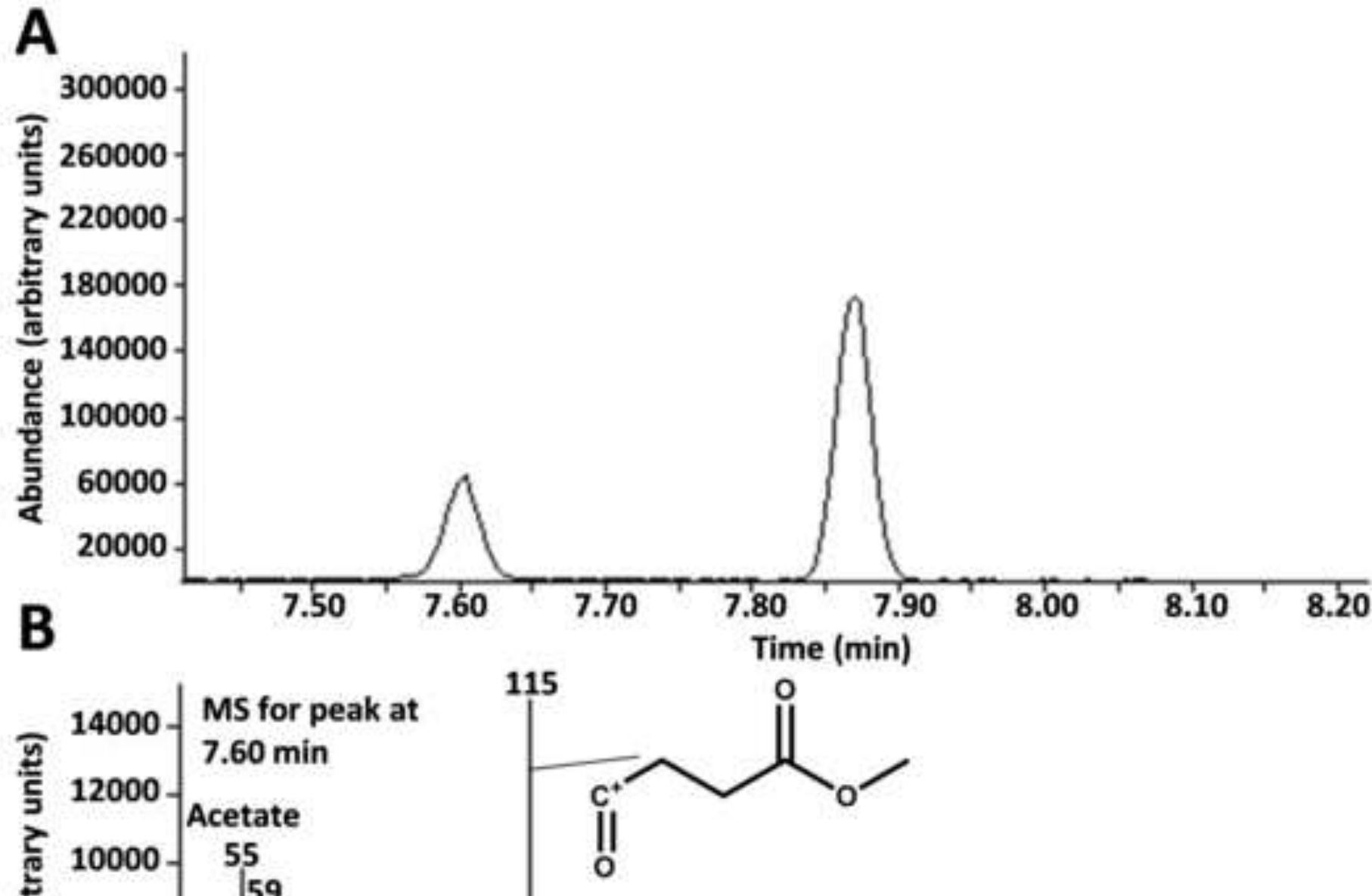

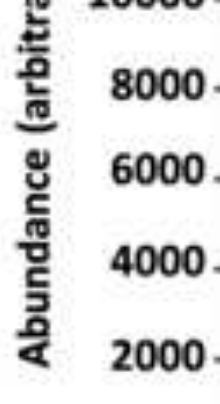

59
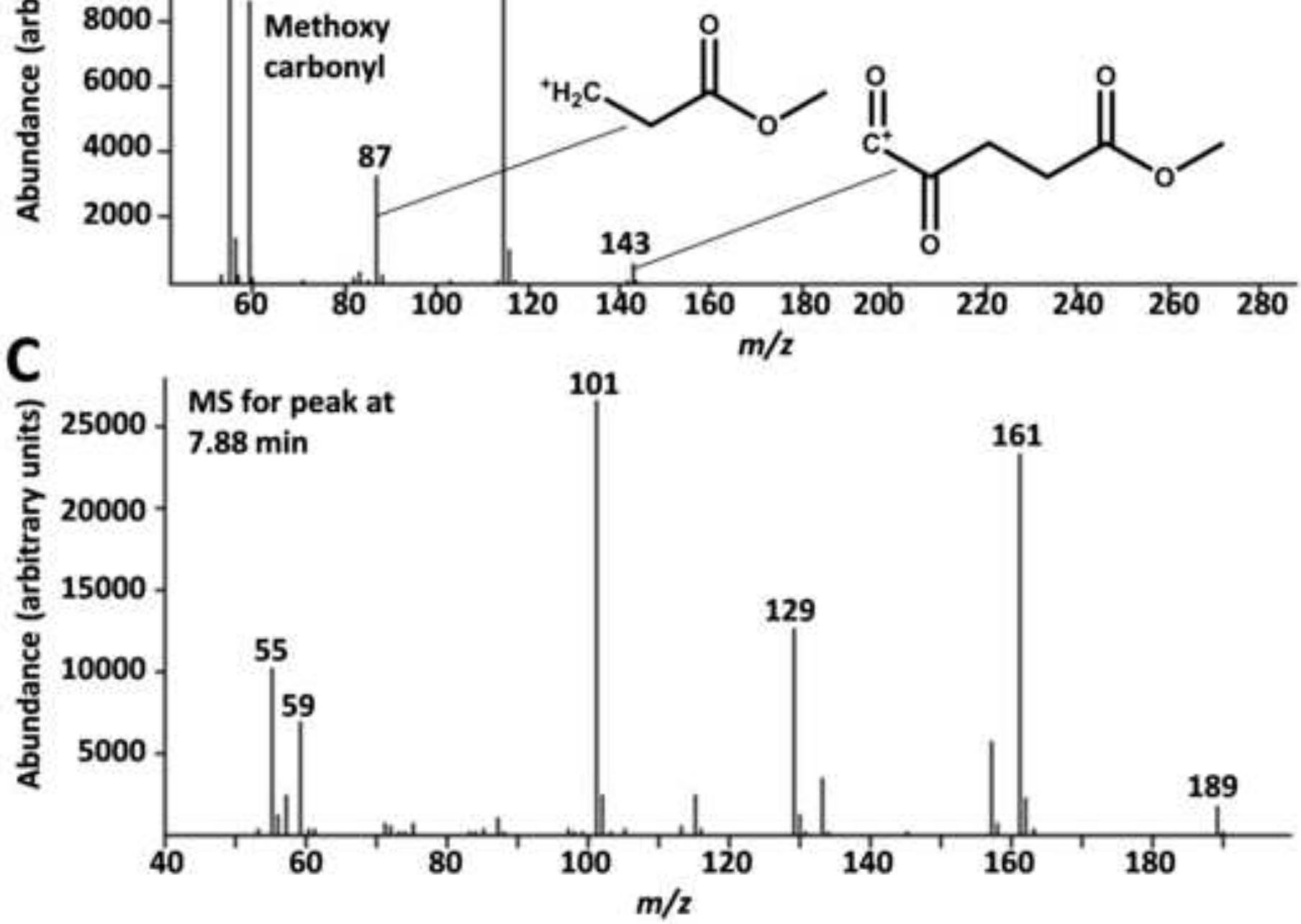
A SIC for duckweed extract, methylated with methanolic $\mathrm{HCL}$

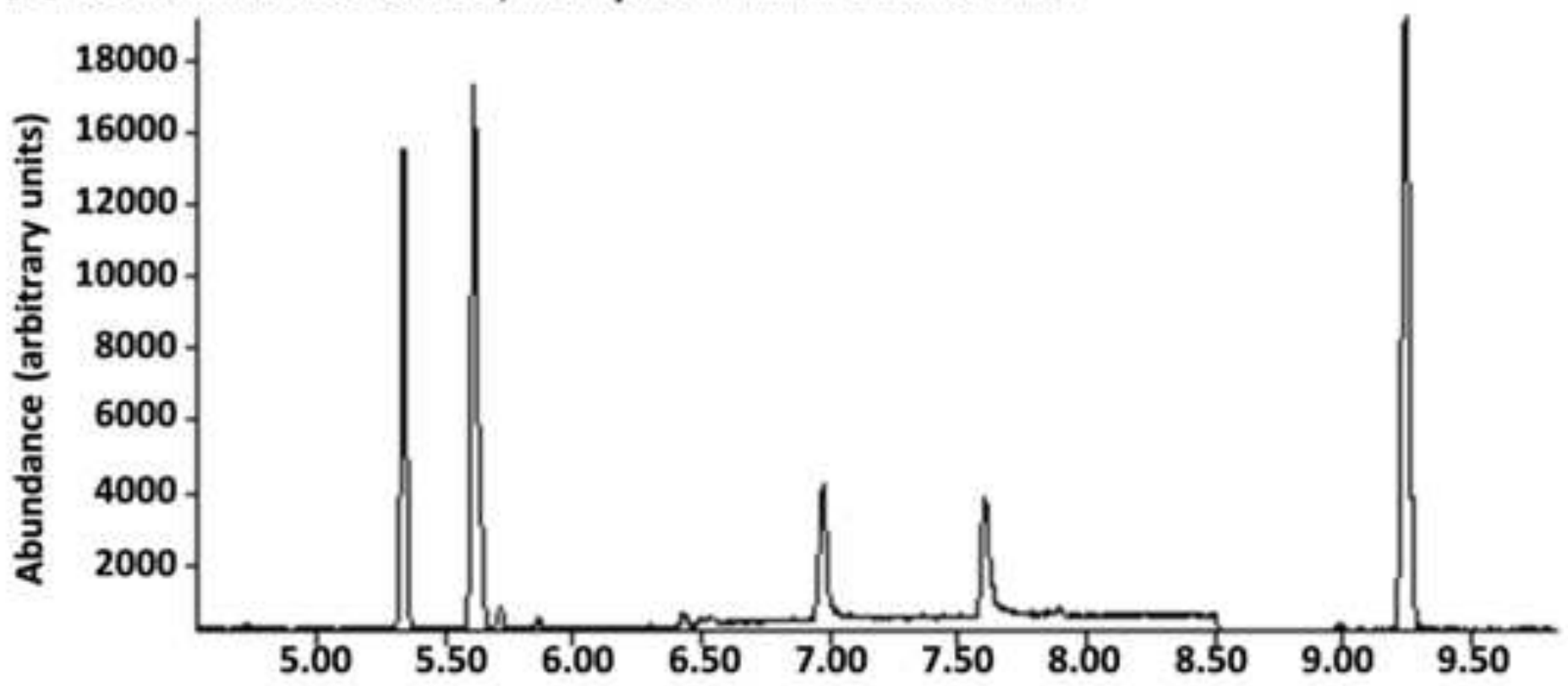

B SIC for duckweed extract, methylated with (TMS)diazomethane

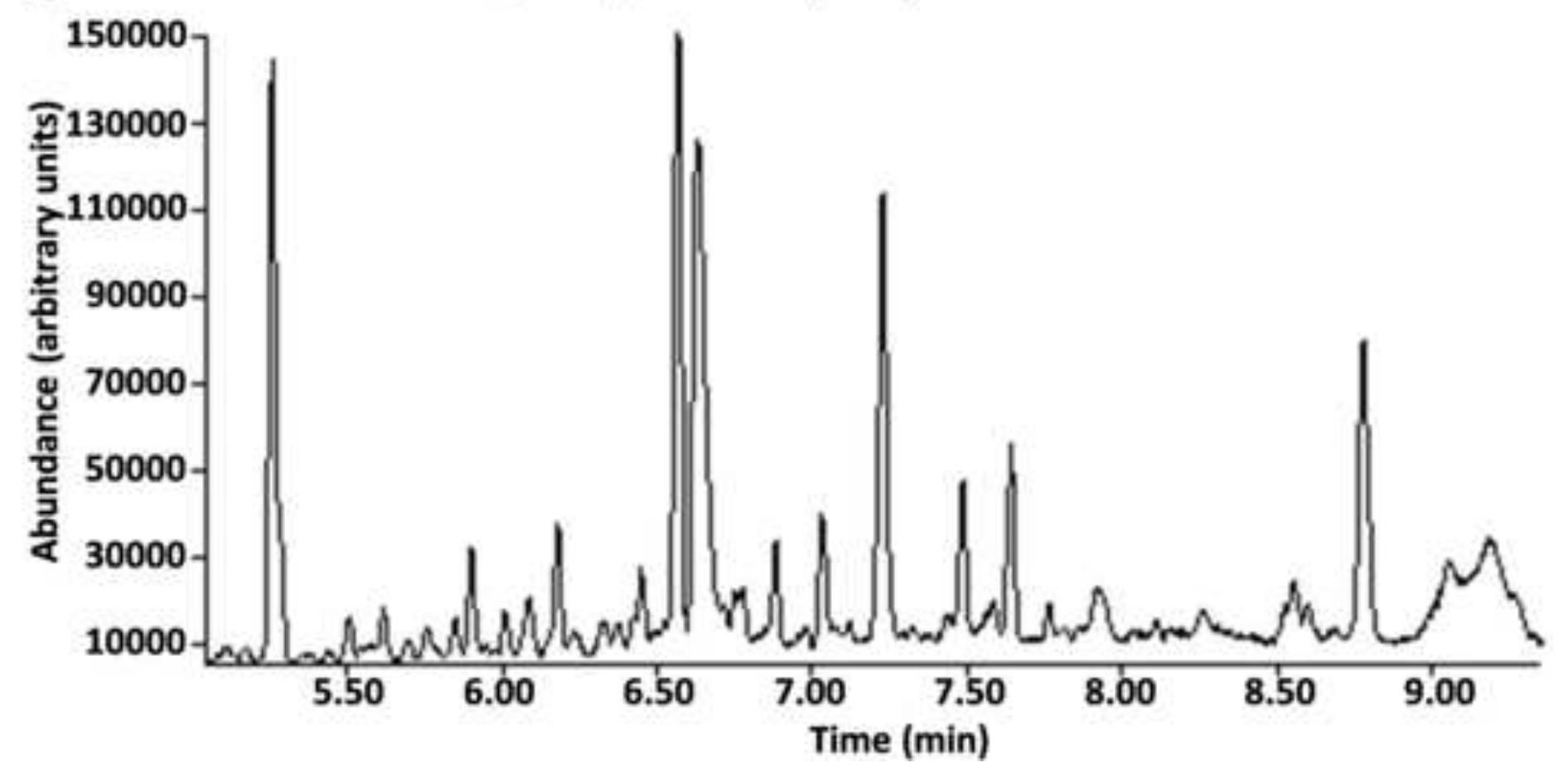




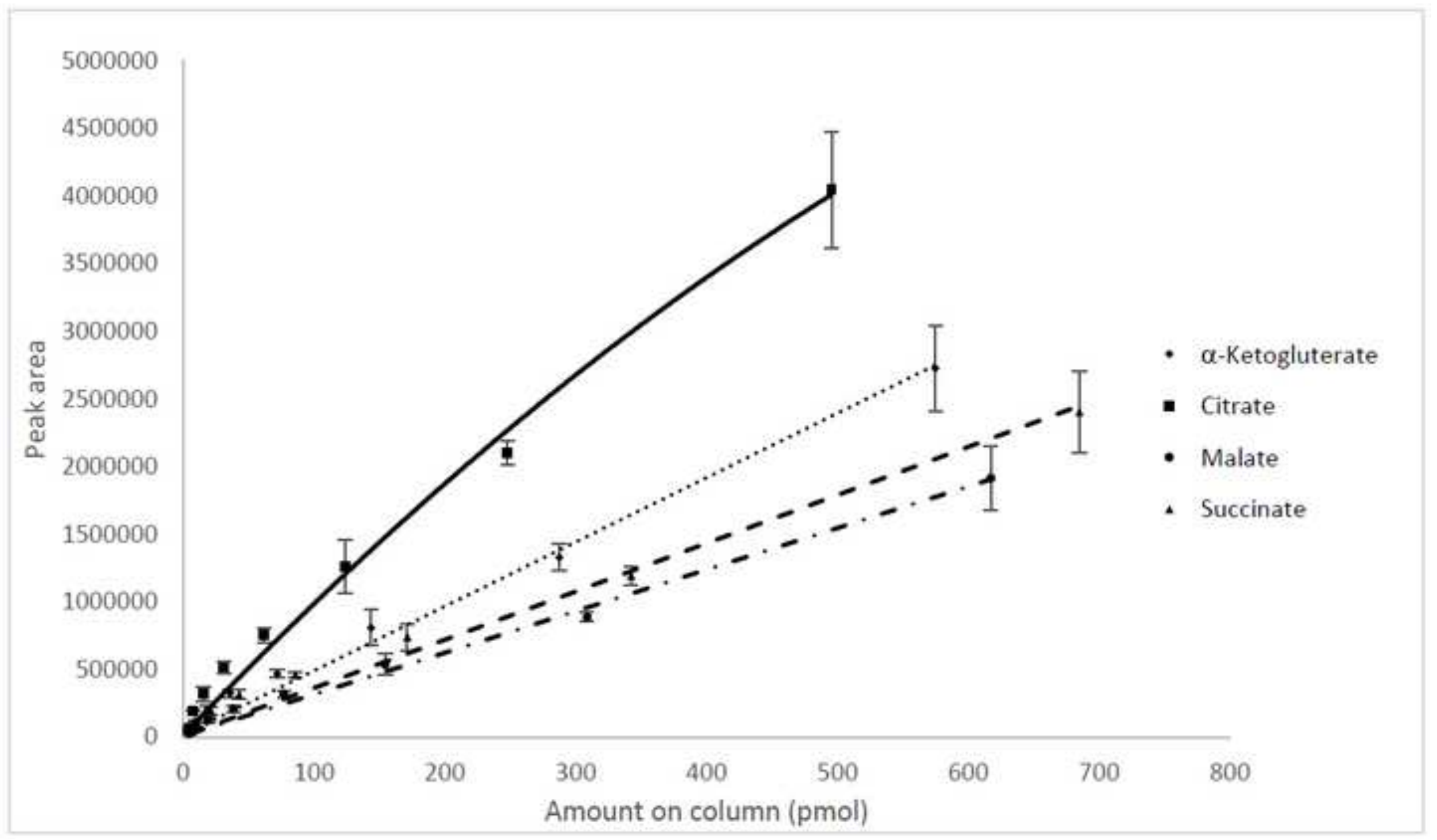

